\section{THE NETWORKING OF MAINTENANCE ENTITIES FOR PRODUCTION AND OTHER PROCESSES}

\author{
LIBOR NECAS, JOSEF NOVAK \\ Dept. of Mechanical Technology, Faculty of Mechanical \\ Engineering, VSB - Technical University of Ostrava
}

DOI: 10.17973/MMSJ.2021_12_2021109

libor.necas@vsb.cz

The high share of maintenance costs in manufacturing processes and their continuing low efficiency lead to a search for solutions to this problem not only in the organization and management of internal maintenance, but also in outsourcing and interconnecting the maintenance entities into separate but cooperating partner units. The creation of business networking, recently applied in manufacturing processes, offers significant potential for efficiency in specific fields of manufacturing and other equipment maintenance. Applying such a system can increase flexibility, professionalism, operability and the quality of maintenance through new digital, virtual, organizational and working forms.

This article deals with the assessment of the possibility of creating business networks for maintenance processes within production and non-production operations, which use machinery and other equipment for their activities, and it also deals with a demonstration of the significant economic and non-economic benefits. It is based on process analysis of the company Vitkovice Heavy Machinery (VHM), University Hospital Ostrava and on research in other industrial companies.

KEYWORDS

business networks, maintenance, TPM, system, costs, savings, metallurgical production

\section{MANUFACTURING PLANT MAINTENANCE SYSTEM REQUIREMENTS}

The main objective of the improvement of the maintenance management system is to prevent the occurrence of failures, operating accidents and breakdowns, and thus to increase the operability of manufacturing equipment, increase its performance, or increase the quality of production. From the economic point of view, the main task is to increase the efficiency of maintenance processes at optimal costs for these activities.

In connection with the results of a number of studies in the field of maintenance work in Czech companies, the basic and general problem is the persistence of companies in the traditional form of maintenance after a failure. The argument for not implementing Productive (PM2), Total Productive Maintenance (TPM), or Total Integrated Maintenance (TIM) systems is, completely illogically, the lack of time and resources - resources that these systems can demonstrably save. Various studies that we carried out in industrial (company Vítkovice Heavy Machinery, CZ) and non-manufacturing companies
(University Hospital Ostrava, CZ) have shown that the above-mentioned maintenance systems save costs and increase operability. [Necas 2020]

\section{Productive Maintenance (PM2)}

- Achieving and maintaining the operational condition of equipment

- Achieving the required quality

- Achieving the required deadlines

- Achieving the planned costs

\section{Total Productive Maintenance (TPM)}

- Machine and equipment efficiency (proactive maintenance)

- Preventive (with shutdown) and predictive (without shutdown) maintenance

- Involvement of all maintenance personnel (including equipment operators) in maintenance activities

\section{Total Integrated Maintenance (TIM)}

This is a TPM integrated into the company's management system. It is a system that leads to digital factories in the field of maintenance.

This hypothesis is illustrated, for example, by Babson College's analysis of the relationship between TPM and manufacturing performance, which is based on structural equation modelling [McKone 2001]. This demonstrates a positive and significant relationship between TPM and low price (based on the four dimensions of cost, quality, delivery and flexibility). Moreover, the relationship between TPM and production output has been complemented here by an indirect relationship of Just-In-Tim procedures, which amplifies this effect

\section{PRINCIPLES AND POTENTIAL OF NETWORKING SUBJECTS}

\section{Principles of Business Networking}

The basic prerequisite for the creation of business networks is the autonomy of maintenance entities, i.e. their separation from the parent company or the transfer of maintenance activities to a specialized company in the form of outsourcing. The subsequent phase is then the gradual interconnection into flexible dynamic networks without creating a solid control hierarchy. The aim must be a value-creating process, that is, in the case of maintenance, a process ensuring the operability and quality of manufacturing with optimum cost levels for all cooperating entities.

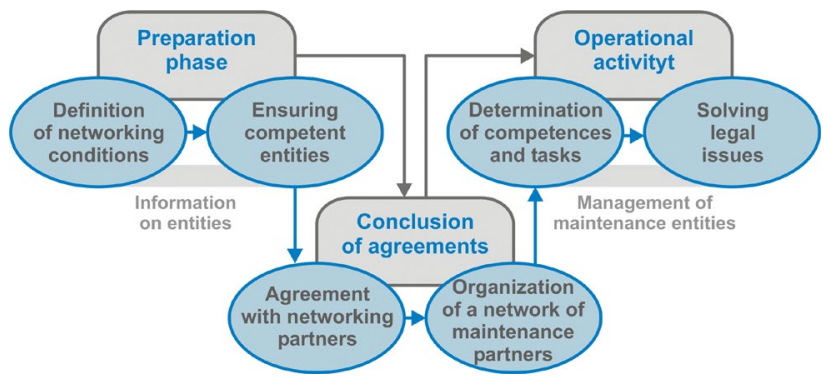

Figure 1. Creating networks for maintenance processes

The maintenance networking process can be divided into the preparation phase, conclusion of agreements phase and operational activities phase (see Figure 1). As a first step, it is 
necessary to formulate the requirements, organize them and define competences. The next step is to find a consensus among partners and to create an organizational system. The actual process of maintenance provided by the network consists of assigning tasks and solving the legal issues involving mutual relations. [Tomek 2017]

\section{Positive Effects of Business Networking}

The emergence of the Company Network leads to a distribution of the risk of economic failure among all members of the network. It offers companies new contracts which they would not have obtained if they were operating independently on the market and whose conditions they would not meet in terms of capacity or other requirements. In addition, the interconnected capacity is flexible within the system thanks to the possibility of connecting other entities. Last but not least, networking companies can achieve their goals much faster, with better quality, and much cheaper due to cost sharing with others. [Necas 2017]

\section{Weaknesses of Business Networking Systems}

Business networking, however, also has some negatives. These include the waiver of part of one's own exclusivity, a certain risk of interdependence resulting from the shared use of resources, and the impossibility of building one's own future core competence. Equally, participation in joint financial benefits can be a complication.

\section{Prerequisites for the Successful Networking of Maintenance Entities}

To create a network of maintenance companies that meets expectations, it is necessary to secure strong motivation, connection and consensus on the goals, activity and presence of the dominant link, as well as mutual trust. Moreover, the networking process requires sufficient time and space for members to interact and their ability to perceive a common identity. Only in this way will the full functionality of the created network be achieved.

The building of corporate networks and the evaluation of their benefits has been addressed in the recent past, for example, in a study at UTN (Facultad Regional Santa Fe, Argentina), which described the main organisational structure and relationships, information flows, management roles, actor behaviour and constraints in the network on the basis of a corporate model. This model was based on the process of a new pharmaceutical product in a network of SMEs in the specialty chemical sector [Canavesio 2007].

\section{MAINTENANCE PROCESSES AND NETWORKING POSSIBILITIES}

The effectiveness of the maintenance management system is also strongly influenced by its integration within the corporate organizational structure (see Figure 2). The functionality, scope and character vary depending on the degree of the centralization of maintenance processes and possible exclusion from the internal organizational system outside, towards external maintenance service providers.

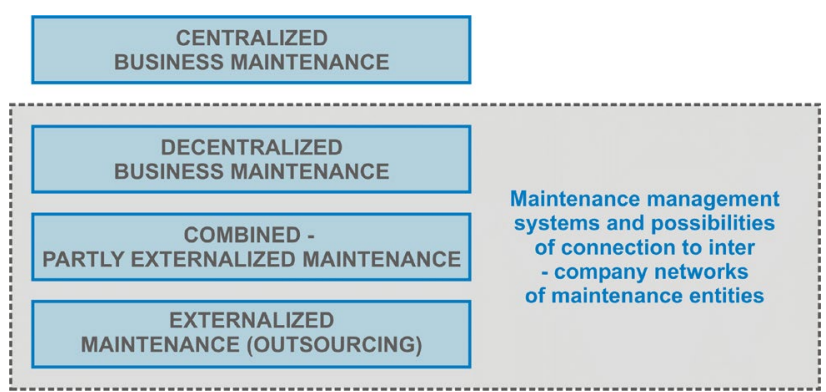

Figure 2. Organization of the maintenance management system and networking possibilities

A decentralized maintenance management system, its outsourcing or combined form, provide the prerequisite for the interconnection of partial maintenance activities into functional and effective networks.

\section{Fields of Maintenance Activities and Subjects of Their Execution}

Eight fields can be identified in terms of the activities that each networked maintenance system should perform (Figure 3):

A. Software security management of maintenance processes in the network - this technical support for the interconnection of information and management processes should ensure the input and processing of information, mutual communication, demand records and capacity blocking. Furthermore, it should create interfaces for access to the database according to authorization systems and secure the field of document creation and printing.

B. Database for maintenance objects activities - technical support for sharing labour and material consumption stored in autonomous or central maintenance network databases.

C. Diagnostics database (vibro, thermo, tribo)- technical support for data sharing to perform and evaluate machine and production equipment diagnostics, again within autonomous or central databases.

D. Database for structural components - technical support to simplify and shorten the search for a set of 2D and 3D documentation of machines, equipment and their parts divided into details of individual parts, as required by practice.

E. Maintenance inventory (storage and inventory management) - linking the maintenance process with a comprehensive range of spare parts, tools and materials to meet the needs of network operators in terms of both material and time - so as to avoid the unnecessary unavailability of production equipment and uneconomical retainment of resources in inventories.

F.-H. Electrical maintenance, machine maintenance and measurement and control maintenance - a wide range of maintenance activities structured according to their specific requirements for the qualifications of staff, their equipment and organizational needs.

Particularly the area of creating a data base for standards and control of assembly work, maintenance and auxiliary service activities, as well as building software support for these systems, has long been dealt with at the Faculty of Mechanical Engineering of VSB - Terchnical University Ostrava by a team led by Associate Professor Josef Novák. 


\section{Creation of Networks for Maintenance Activities}

The proposed maintenance system consists of a network of maintenance entities (Fig. 3; U1, U2...) interconnected without a common control centre, in which each entity offers one or more activities (Fig. 3; A, B...). Individual entities (companies) are then involved in accordance with their strategy, within the field of their maintenance competencies, material dispositions and capacity, and provide each other with insufficient capacity or overcapacity within the network. With the effect of mutual synergy, the involved companies then execute the maintenance within the framework of contracts concluded with their customers (Fig. 2; Fy1, Fy2...).

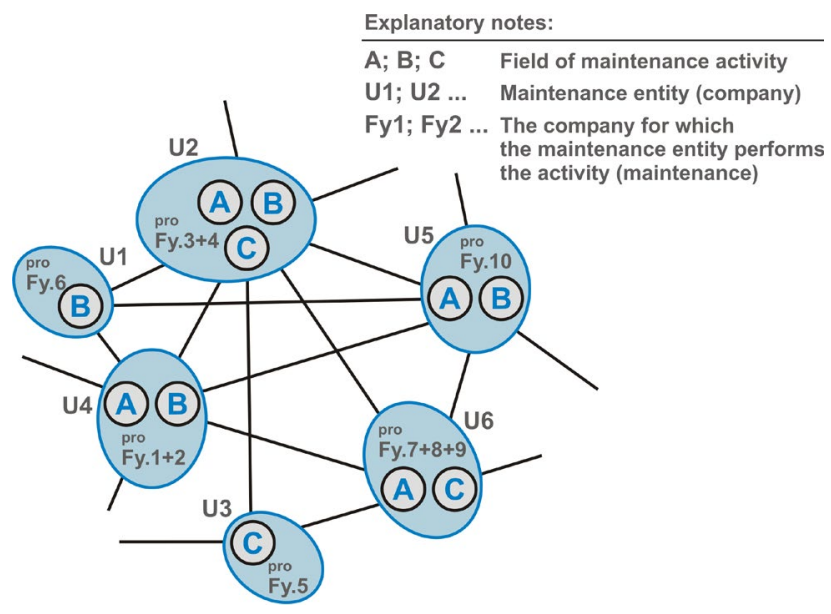

Figure 3. Organization of the maintenance management system and networking options

The network of entities providing maintenance activities created in this way should operate as an open and flexible system, allowing entities to enter the system or leave it. On the other hand, the companies must behave within the established rules for direct and indirect coordination on the market, network culture and mutual trust. Good contractual legal security, including networking conditions and mutual legal protection of integrated entities is also necessary. [Tomek 2017]

\section{MAIN BENEFITS OF MAINTENANCE NETWORKING}

Through the networking of maintenance entities a number of positive effects can be achieved. These effects can be divided into three fields. These are the benefits of building and interconnecting a common or autonomous shared database, the benefits of interconnected, better utilized maintenance capacity, and last but not least, the benefits of maintaining autonomy, strengthening efficiency and development in the field of self-specialization of the entities involved in maintenance networks. [Novak 2012]

\section{a) In the field of supporting information systems:}

- Joint creation and utilization of a large database of activities for an object (e.g. CAS database) and thus creation of a wide database for the evaluation and determination of the consumption of maintenance work.

- Interconnection of the system of diagnostic methods (vibro, thermo and tribo diagnostics) and thus the extension and refinement of fault diagnostics.

- Building and using an extensive system of 2D and 3D drawings depicting the design of the production equipment and possible animation of repairs and parts replacement (GTS, Solid Edge, etc.).

- Creation of unified and sophisticated documents and certificates (Word, Excel, Solid Edge).

- Exchange of information on capacity utilization and underutilization within the networked entities (supply and demand) and elimination of losses in human resources, warehouse management of maintenance, production downtimes caused by maintenance, transportation and logistics, etc.

b) In the field of electrical, machine, measurement and control maintenance:

- Increasing the specialization and expertise of maintenance staff and dealing with complex and less common failures, whose external security outside the network as well as the internal security by the company itself would be economically demanding or unbearable.

- Increasing the availability of modern and technically and financially demanding equipment for complex and highly sophisticated manufacturing equipment of current metallurgical production.

- Improvement of equipment for diagnostics processes in manufacturing equipment and thus an increase of the level of preventive maintenance preventing the occurrence of serious failures and accidents.

\section{c) In other fields:}

- Maintaining the own strategy, subjectivity and relatively high autonomy of maintenance units associated with individual production and other operations.

- Possibility to choose the degree of integration into the network of maintenance entities or only partial involvement within the selected segment of maintenance activities (e.g. only electrical maintenance, machine maintenance or measurement and control maintenance).

- Stability of overhead costs by way of creating a new management level with the number of units necessary for its operation.

\section{CONCLUSIONS}

In many companies, the maintenance process is considered to be a less important activity, as it usually does not, in the opinion of company management, primarily contribute to the creation of the economic effect. However, neglecting this is all the more apparent in the event of a manufacturing equipment failure. The impact on profits is then considerable. Whatever attitude the company may take toward maintenance, appropriate involvement in an inter-company network of maintenance activities can have a significant positive effect on it, not only in terms of manufacturing equipment operating at optimal cost, but also in terms of the efficient use of maintenance capacities and the profit that this business activity can bring.

A company, therefore, has a number of options. Either to exclude maintenance from the portfolio of its activities and join the network as a customer requesting it as a service, to engage as an entity providing its excess of maintenance capacity (technical, personnel, material, data, etc.), or to focus entirely on this field within the company and build its own business plan on it. 


\section{REFERENCES}

[Canavesio 2007] Canavesio, M.M., Martinez, E. Enterprise modeling of a project-oriented fractal company for SMEs networking. Computers in Industry, Volume 58, Issues 8-9, December 2007, pp. 794-813

[Cada 2013] Cada, R. Testing of strain in stampings by embossed grids. Technical Gazette, 2003, Vol. 10, No. 3-4, pp. 9-13. ISSN 1330-3651. EID: 2-s2.0-1842865587.

[Cada 1997] Cada, R. Formability of deep-drawing steel sheets. In: Proceedings of the 5th European Conference on Advanced Materials and Processes and Applications (EUROMAT 97): Materials, Functionality Design: Volume 4 - Characterization and Production/Design. Red. L. A. J. L. Sarton a H. B. Zeedijk. Netherlands, Maastricht: Netherlands Society for Materials Science, 1997, pp. 463-466. ISBN 90-803513-4-2.

[McKone 2001] McKone, K.E., Schroeder, R.G., Cua, K.O. The impact of total productive maintenance practices on manufacturing performance Journal of Operations Management, 19 (1) (2001), pp. 39-58.

[Necas 2020] Necas, L. Training and practice to ensure implementation of the TPM system. MM science journal [electronic source], 2020, November 2020, online, No. 4, pp. 4124-4127, ISSN 1805-0476, DOI: 10.17973/MMSJ.2020_11_2020043

[Necas 2017] Necas, L. et al. The effectiveness of the implementation of new management systems in maintenance for metallurgical production. In: METAL 2016: conference proceedings: (reviewed version): 25th Anniversary International
Conference on Metallurgy and Materials: May 25th-27th 2016, Hotel Voronez I, Brno, Czech Republic, EU. Ostrava: Tanger, 2016. pp. 1943-1949. ISBN 978-80-87294-67-3.

[Novak 2012] Novak, J. Consulting point for cooperation development in the field of innovations and transfer of technologies. VSB - Technical University of Ostrava, 2012, Ostrava [online]. C2012 [cit. 16.11.2019]. Available from: http://cp.forever.cz/

[Schindlerova 2016] Schindlerova, V., Ivana Sajdlerova a Pavel Zmeskal. Implementation of the Principles of TPM in Field of Maintenance Preparations. Sbornik vedeckych praci Vysoke skoly banske-Technicke univerzity Ostrava, Rada strojni. VSB TU Ostrava, 2016, vol. LXII(1), pp. 51-57. ISSN 1210-0471.

[Schindlerova 2020] Schindlerova, V., Sajdlerova, I., Michalcik, V., Nevima, J., Krejcí, L. Potential of Using TPM to Increase the Efficiency of Production Processes. Tehnicki vjesnik - Technical Gazette. Osijek: University of Osijek, 2020, 27(3), pp. 737-743. ISSN 1330-3651.

[Tomek 2017] Tomek, G. and Vavrova, V. Prumysl 4.0, aneb, Nikdo sam nevyhraje. Praha: Professional Publishing, 2017. ISBN 978-80-906594-4-5.

\section{CONTACTS}

Ing. Libor Necas, Ph.D.

VSB - Technical University of Ostrava, Faculty of Mechanical Engineering, Department of Mechanical Technology

17. listopadu 2172/15, Ostrava-Poruba, 70800 Ostrava, Czech Republic, e-mail: libor.necas@vsb.cz 